\title{
Atributos físicos e químicos de um Latossolo submetido à aplicações sucessivas de cama de peru em pastejo rotacionado
}

\author{
Diego Oliveira Ribeiro ${ }^{1,2}$, Gustavo Castoldi ${ }^{2}$, Carlos Ribeiro Rodrigues ${ }^{2}$, Andrisley Joaquim da Silva ${ }^{1}$, Rogério
} Machado Pereira ${ }^{1}$, Gabriela Maria Kuss ${ }^{1}$

1. Centro Universitário de Mineiros - UNIFIMES, Mineiros, GO. 2. Instituto Federal Goiano - IF- GOIANO, Campus Rio Verde, Rio Verde, GO. E-mail: diego@unifimes.edu.br

\section{Resumo}

Grandes quantidades de resíduos da agroindústria avícola são produzidas em áreas próximas aos criadouros, e muitas vezes esses resíduos são usados como fonte de adubação em pastagens, podendo alterar os atributos químicos e físicos do solo. O presente estudo objetivou avaliar os efeitos de aplicações de doses contínuas ao longo do tempo (até oito anos) de cama de peru nos atributos químicos e físicos de um Latossolo Vermelho distroférrico sob pastejo rotacionado. A área experimental foi dividida em 16 piquetes de 0,5 ha cada, e cultivada com Uroclhoa decumbens em sistema de pastejo rotativo. Os tratamentos foram dados por doses acumuladas de cama de peru, com aplicações anuais desde 2008 até o ano de 2015, sendo os seguintes: controle, 35,29; 51,79 e 66,24 Mg ha ${ }^{-1}$. O uso continuado de cama de peru por pelo menos 5 anos $\left(35,29 \mathrm{Mg} \mathrm{ha}^{-1}\right)$ promoveu incrementos nos teores de fósforo, potássio e a saturação por bases, além de reduzir a acidez e a saturação por alumínio. Alterações na matéria orgânica do solo, no entanto, foram encontradas somente após até 8 anos $\left(66,24 \mathrm{Mg} \mathrm{ha}^{-1}\right)$ de uso contínuo de cama de peru. Houve pouco efeito da utilização de cama de peru na relação Ca:Mg e também nos atributos físicos do solo, exceto pela macroporosidade na camada superficial, que foi maior nas doses intermediárias de cama de peru.

Palvavras-chave: dejeto aviário; Urochloa decumbens; atributos químicos do solo; matéria orgânica.

\section{Physical attributes and fertility of a Hapludox subjected to successive turkey manure applications in rotational pasture}

\begin{abstract}
Large amounts of poultry agroindustry residues are produced in areas near the breeding grounds, and often these residues are used as a source of fertilization in pastures, which may affect the chemical and physical attributes of the soil. The aim of this study was to evaluate the effects of continuous application over time (up to eight years) of turkey manure on the chemical and physical attributes of an Oxisol under rotational grazing. The experimental area was divided into 16 plots of 0.5 ha each, and cultivated with Uroclhoa decumbens in rotational grazing system. Treatments were given by accumulated doses of turkey manure, with annual applications from 2008 to 2015, as follows: control, 35.29; 51.79 and $66.24 \mathrm{Mg} \mathrm{ha}^{-1}$. Continued use of turkey manure for at least 5 years $\left(35.29 \mathrm{Mg} \mathrm{ha}^{-1}\right)$ promoted increases in phosphorus, potassium and base saturation, as well as reducing acidity and aluminum saturation. Changes in soil organic matter, however, were found only after 8 years $\left(66.24 \mathrm{Mg} \mathrm{ha}^{-1}\right)$ of continuous use of turkey manure. There was little effect of turkey manure use on $\mathrm{Ca}: \mathrm{Mg}$ ratio and also on soil physical attributes, except for macroporosity in the superficial layer, which was higher in intermediate doses of turkey manure.
\end{abstract}

Keywords: poultry litter. Urochloa decumbens. soil chemical attributes; organic matter. 


\section{Introdução}

No ano de 2016, o Estado de Goiás foi o segundo maior exportador de carne de peru, e o sexto maior exportador de carne de frango, sendo responsável por 23,2 e $4,2 \%$, respectivamente, das exportações totais brasileiras (ABPA, 2017). A produção dessa grande quantidade de proteína animal gera grandes quantidades de resíduos como a cama de peru, sendo imprescindível dar aos mesmos um destino apropriado, a fim de minimizar os danos que podem causar ao meio ambiente. Quando manejados adequadamente, esses resíduos animais podem ser utilizados na atividade agropecuária como adubo orgânico (PINTO et al., 2012; RIBEIRO et al., 2017; COUTO et al., 2017; SILVA et al., 2018).

Tais resíduos podem ser utilizados como única fonte de nutrientes (PINTO et al., 2012), ou em substituição total em pastagens (SILVA et al., 2018). O uso contínuo desses dejetos pode acarretar em alterações nos estoques de carbono (C) e nitrogênio ( $N$ ), bem como nos atributos químicos e microbiológicos do solo (PINTO et al., 2012). Em regiões tropicais e subtropicais, a matéria orgânica do solo (MOS) é fundamental, pois é a principal fonte de cargas negativas (MEURER, 2012), sendo responsável por adsorver nutrientes catiônicos que poderão ser utilizados pelas plantas. Grandes quantidades de resíduos orgânicos aplicados podem elevar o $\mathrm{pH}$, o teor de fósforo $(P)$, de potássio $(K)$, a saturação por bases (PINTO et al., 2012) e reduzir a saturação por alumínio (OLIVEIRA et al., 2000; PINTO et al., 2012) do solo. Quantidades elevadas de resíduos animais adicionados ao solo em conjunto com corretivos, podem ainda promover aumento nos valores de $P$ remanescente, além de reduzir a capacidade máxima de adsorção de P (SOUZA et al., 2006).

Apesar de promover melhorias em alguns atributos do solo, aplicações contínuas de dejetos animais podem levar a um desbalanço dos nutrientes. Esse desbalanço é dependente da composição dos resíduos, da quantidade aplicada, tempo de aplicação, habilidade da cultura em absorver e exportar nutrientes e tipo de solo (MENEZES et al., 2017). Portanto, aplicações sucessivas de resíduos aviários devem ser monitoradas a fim de evitar desbalanceamento de nutrientes no solo, e consequente comprometimento da produtividade das culturas.
Além dos atributos químicos e biológicos, a utilização de resíduos pode também impactar os atributos físicos do solo (ANDREOLA et al., 2000; GOMIDES; BORGES, 2014). A incorporação de cama de frango no sulco de plantio de cana-deaçúcar, por exemplo, resultou em efeitos positivos na porosidade do solo nas camadas subsuperficiais (GOMIDE; BORGES, 2014). Também nessa mesma cultura, Ribeiro et al. (2016), verificaram elevação da porosidade e redução da densidade do solo em camadas superficiais quando a aplicação da cama de peru ocorreu superficialmente.

Diversos estudos têm sido realizados com a utilização de resíduos orgânicos na atividade agropecuária, porém, ainda são poucos os estudos que tratam dos efeitos do uso contínuo após vários anos de uso de resíduos aviários, particularmente cama de peru, na fertilidade e qualidade física do solo. Objetivou-se, portanto, avaliar as alterações nos atributos químicos e físicos de um Latossolo Vermelho após até oito anos de aplicação contínua de cama de peru em pastejo rotacionado.

\section{Material e Métodos}

O experimento foi desenvolvido na Fazenda Alvorada, localizada no município de Portelândia $\quad\left(17^{\circ} 17^{\prime} 36,45^{\prime \prime} S, \quad 52^{\circ}\right.$ W38'59,66"), região Sudoeste do Estado de Goiás. A região apresenta temperatura média anual de $24,2 \circ \mathrm{C}$ e precipitação pluviométrica média de $1.700 \mathrm{~mm}$. O clima predominante é quente, semiúmido e notadamente sazonal, com verão chuvoso e inverno seco, sendo classificado como "Aw", conforme a classificação de Köppen.

O solo da área experimental foi caracterizado como Latossolo Vermelho distroférrico (SANTOS et al., 2018), apresentando $739 \mathrm{~g} \mathrm{~kg}^{-1}$ de argila, $125 \mathrm{~g} \mathrm{~kg}^{-1}$ de silte e $136 \mathrm{~g} \mathrm{~kg}^{-1}$ de areia, na camada 0-20 cm. A área experimental é composta por 16 piquetes de 0,5 ha cada, que desde 1995 vêm sendo cultivados com Urochloa decumbens, em sistema de pastejo rotacionado para bovinocultura de leite. O período de permanência dos animais em cada piquete variou de um a dois dias de ocupação, conforme a oferta de forrageira.

O experimento foi implantado em 2008, adotando-se um delineamento de blocos casualizados, com quatro doses acumuladas de cama de peru $\left(0 ; 35,29 ; 51,79\right.$ e $66,24 \mathrm{Mg} \mathrm{ha}^{-1}$, correspondendo respectivamente a $0 ; 5 ; 7$ e 8 
anos sucessivos de aplicações anuais de cama de peru) e quatro repetições. A parcela principal foi constituída por doses acumuladas de cama de peru, as diferentes profundidades analisadas foram consideradas como subparcelas. A cama de peru foi aplicada in natura, superficialmente a lanço com distribuidor de fertilizantes orgânicos, sempre no início da estação chuvosa, no mês de outubro. O histórico das aplicações está descrito na Tabela 1. 
Tabela 1. Histórico de aplicação de cama de peru na área experimental e quantidade fornecida (acumulada) de $\mathrm{N}, \mathrm{P}, \mathrm{K}, \mathrm{Ca}, \mathrm{Mg}$ e C.

\begin{tabular}{|c|c|c|c|c|c|c|c|c|c|c|c|c|c|c|}
\hline $\begin{array}{c}\text { Dose } \\
\text { Acumulada }\end{array}$ & 2008 & 2009 & 2010 & 2011 & 2012 & 2013 & 2014 & 2015 & $\mathrm{~N}$ & $\mathrm{P}_{2} \mathrm{O}_{5}$ & $\mathrm{~K}_{2} \mathrm{O}$ & $\mathrm{CaO}$ & $\mathrm{MgO}$ & C-org \\
\hline $\mathrm{Mg} \mathrm{ha}^{-1}$ & \multicolumn{9}{|c|}{------Quantidade aplicada $\left(\mathrm{Mg} \mathrm{ha}^{-1}\right)$ em cada ano ----- } & \multicolumn{5}{|c|}{ - } \\
\hline 0 & 0 & 0 & 0 & 0 & 0 & 0 & 0 & 0 & 0 & 0 & 0 & 0 & 0 & 0 \\
\hline 35,29 & 0 & 0 & 0 & 7,89 & 7,34 & 5,71 & 5,71 & 8,64 & 1.035 & 1294 & 905,4 & 1.035 & 232,8 & 7.968 \\
\hline 51,79 & 0 & 7,81 & 8,69 & 7,89 & 7,34 & 5,71 & 5,71 & 8,64 & 1.518 & 1.898 & 1.329 & 1.518 & 341,6 & 11.692 \\
\hline 66,24 & 14,45 & 7,81 & 8,69 & 7,89 & 7,34 & 5,71 & 5,71 & 8,64 & 1.942 & 2.428 & 1.699 & 1.942 & 436,9 & 14.953 \\
\hline
\end{tabular}


O resíduo utilizado como adubo orgânico foi originado de dejetos provenientes da criação de peru, com cama à base de maravalha, apresentando a seguinte composição (média das aplicações): C-orgânico $=308 \mathrm{~g} \mathrm{~kg}^{-1} ; \mathrm{N}=4 \% ; \mathrm{P}_{2} \mathrm{O}_{5}$ $=5 \% ; \mathrm{K}_{2} \mathrm{O}=3,5 \% ; \mathrm{Ca}=4,0 \% ; \mathrm{Mg}=0,9 \%$; relação $\mathrm{C}: \mathrm{N}=10 / 1$; matéria seca $=73,3 \%$; $\mathrm{pH}$ em água $=$ 7,7 (TEDESCO et al., 1995).

Após a implantação do experimento, a taxa de lotação foi fixada em 20 a 25 animais da raça Girolando no período de chuva (outubro a maio), com peso vivo entre 550 e $600 \mathrm{~kg}$. No período da seca (junho a setembro), os animais foram tratados com silagem de milho durante o dia e a noite pastejaram nos piquetes do experimento. Após cada aplicação do resíduo, a área experimental ficou em repouso por 45 dias.

A amostragem de solo para análise física foi realizada em novembro de 2016. Para a análise química foram coletadas oito amostras de cada piquete, utilizando-se trado holandês e nas camadas de 0 a $5 \mathrm{~cm}, 5$ a $10 \mathrm{~cm}$ e 10 a $20 \mathrm{~cm}$. Essas amostras foram secas ao ar e peneiradas em malha de $2 \mathrm{~mm}$, sendo analisadas quanto aos teores de MOS, $\mathrm{P}, \mathrm{pH}$, bases, CTC e granulometria (TEIXEIRA, 2017). As análises físicas de densidade do solo (Ds), volume total de poros (VTP), macroporosidade (Ma) e microporosidade (Mi) foram realizadas em amostras indeformadas coletadas nas camadas de 0 a $5 \mathrm{~cm}, 5$ a $10 \mathrm{~cm}$ e 10 a $20 \mathrm{~cm}$, utilizando-se um trado tipo Uhland, com anéis metálicos de altura e diâmetro de $5 \mathrm{~cm}$ (volume de $98 \mathrm{~cm}^{3}$ ), em dois pontos por parcela. A densidade do solo foi determinada pela relação entre a massa seca e o volume total do solo coletado, e as análises de porosidade total, macroporosidade e microporosidade foram realizadas em mesa de tensão, a $6 \mathrm{kPa}$ (TEIXEIRA et al., 2017).

Para a comparação das doses de cama de peru, dentro de cada uma das camadas de solo, os resultados das análises químicas e físicas do solo foram submetidos à análise de variância, e as médias dos tratamentos comparadas pelo teste de Tukey, a $5 \%$ de probabilidade. As análises foram realizadas com o auxílio do programa computacional Sistema para Análise de Variância - SISVAR versão 5.6 (FERREIRA, 2011).

\section{Resultados e Discussão}

Os valores de $\mathrm{pH}$ aumentaram à aplicação de cama de peru (Tabela 2). $O$ efeito positivo com a utilização de cama de peru sobre o pH limitouse a camada de 0 a $5 \mathrm{~cm}$ e 10 a $20 \mathrm{~cm}$. Apesar da camada de 5 a $10 \mathrm{~cm}$, não ter tido diferenças significativas, observou-se uma tendência de aumento do $\mathrm{pH}$ com o uso de cama de peru, independentemente da dose utilizada de cama de peru. É possível notar que com apenas 5 anos após a adoção com o uso de cama eleva-se o pH do solo. Esse efeito sobre $\mathrm{o} p \mathrm{pH}$ do solo proporcionou redução da saturação de alumínio em todas as profundidades nos tratamentos em que se utilizou cama de peru (Tabela 2). $\mathrm{Na}$ camada superficial a dose de $51,79 \mathrm{Mg} \mathrm{ha}^{-1}$ proporcionou a maior redução na saturação por alumínio saindo de 37,15 para $0,4 \%$. 
Tabela 2. Atributos químicos de um Latossolo Vermelho distroférrico manejado sob sistema rotacionado de pastejo em função de doses acumuladas de cama de peru.

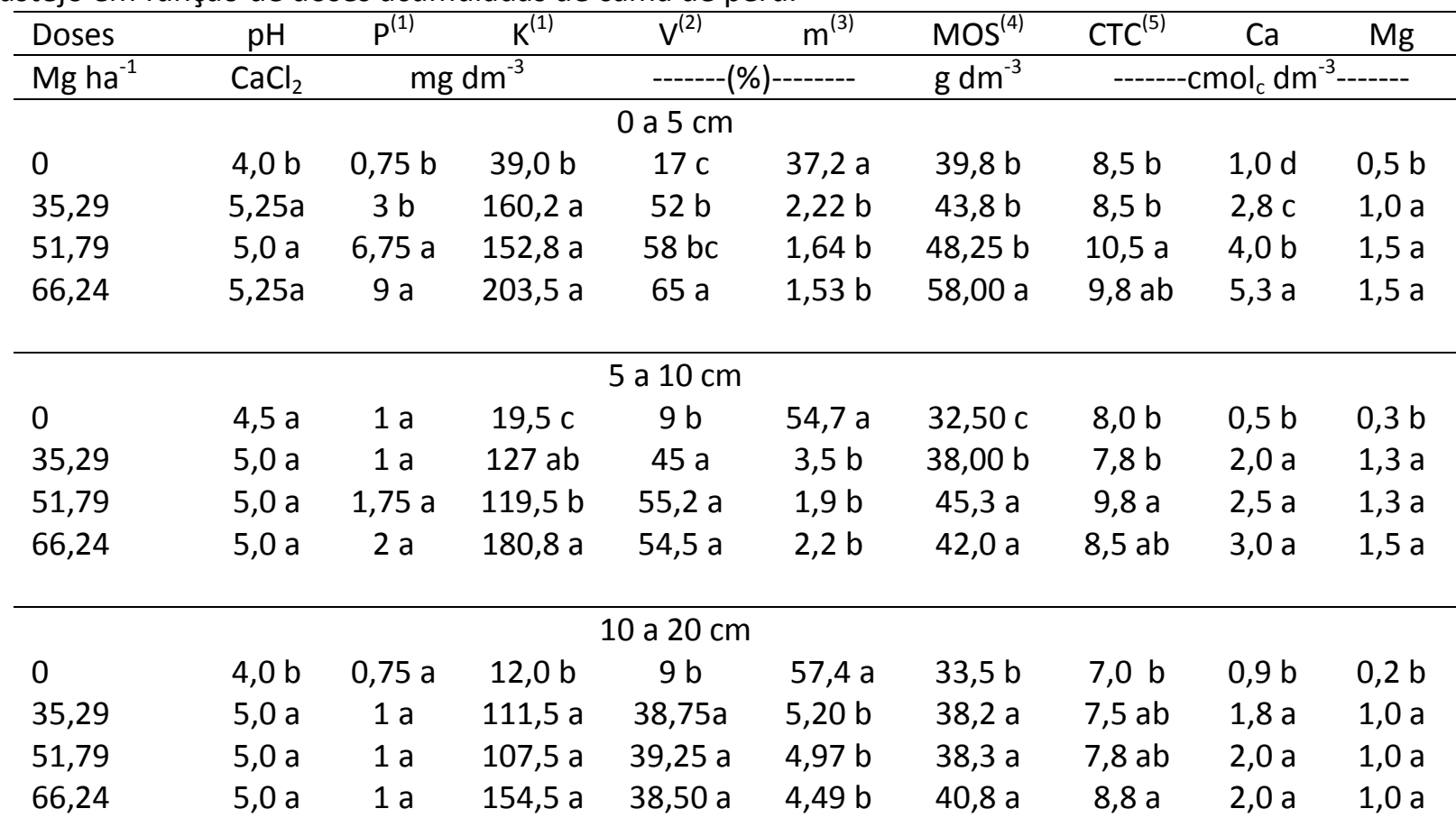

Médias seguidas por mesma letra não diferem entre si pelo teste de Tukey a $5 \%$ de probabilidade. Extrator Mehlich 1. ${ }^{(2)}$ Saturação por bases; ${ }^{(3)}$ Saturação por alumínio. ${ }^{(4)}$ Matéria orgânica do solo. ${ }^{(5)}$ Capacidade de troca de cátions.

Esse efeito sobre $\mathrm{o} \mathrm{pH}$ do solo proporcionou redução da saturação de alumínio em todas as profundidades nos tratamentos em que foi utilizado cama de peru, não apresentando diferenças entre os mesmos. Os aumentos das doses de cama proporcionaram redução da saturação de alumínio saindo de 37,15; 54,67 e 57,39 para 1,53; 2,16 e 4,49 respectivamente da testemunha para a maior dose utilizada de cama de peru $\left(66,24 \mathrm{Mg} \mathrm{ha}^{-1}\right)$ nas profundidades de $0 \mathrm{a}$ 5,5 a 10 e 10 a $20 \mathrm{~cm}$.

A utilização de cal como substância utilizada para desinfecção da cama e redução da carga de patógenos (RONDÓN, 2008) possivelmente foi responsável pela alto valor de $\mathrm{pH}$ da cama de peru utilizada, que era de 7,8. A cal tem efeito corretivo de acidez, de modo que a aplicação de resíduos que apresentam cal, particularmente quando utilizado sucessivamente e em elevadas quantidades (PINTO et al., 2012), pode elevar o $\mathrm{pH}$ na camada mais superficial do solo (Tabela 2). Este fato pode estar relacionado com a hidrólise desse elemento que ocorre em valores de $\mathrm{pH}$ acima de 5 , ocasionando a sua precipitação do Alumínio devido ao anulamento de suas cargas. Tal redução também pode estar relacionada com a capacidade da matéria orgânica formar complexos com alguns elementos, o que acaba por reduzir sua disponibilidade do alumínio para as plantas (OLIVEIRA et al., 2000; PINTO et al., 2012).

Os valores de MOS foram influenciados em todas as camadas avaliadas (Tabela 2). $\mathrm{Na}$ camada de 0 a $5 \mathrm{~cm}$, a maior dose de cama de peru (referente a oito anos de seu uso) resultou em maior teor de MOS. Na camada de 5 a $10 \mathrm{~cm}$, as doses 66,24 e $51,79 \mathrm{Mg} \mathrm{ha}^{-1}$ de cama de peru foram superiores à menor dose de cama de peru, bem como ao tratamento controle. Já a camada de 10 a $20 \mathrm{~cm}, 5$ anos de adoção do uso de cama de peru já foi capaz de superar o tratamento controle em relação aos teores de MOS.

Em relação ao tratamento controle, os teores de MOS nas maiores doses de cama de peru foram superiores em aproximadamente 46 , 29 e $22 \%$ nas camadas de 0 a 5,5 a 10 e 10 a 20 $\mathrm{cm}$ respectivamente. A elevação dos teores de MOS proporcionou consequentemente aumento na CTC (Tabela 2). Nas camadas de 0 a 5 e 5 a 10 $\mathrm{cm}$, a CTC foi superior na dose de $51,79 \mathrm{Mg} \mathrm{ha}^{-1}$ de cama de peru, sendo os tratamentos controle e a menor dose avaliada $\left(35,29 \mathrm{Mg} \mathrm{h}{ }^{-1}\right)$ apresentando a menor CTC, sendo a dose de 66,24 $\mathrm{Mg} \mathrm{ha}^{-1}$ de cama de peru, intermediária 
nessa camada. Na camada de 10 a $20 \mathrm{~cm}$, a maior dose e o tratamento controle apresentaram, respectivamente, a maior e menor CTC. Os demais tratamentos $\left(35,29\right.$ e $\left.51,79 \mathrm{Mg} \mathrm{ha}^{-1}\right)$ apresentaram valores intermediários. Sabendo-se que até $90 \%$ da CTC dos solos tropicais pode ser de origem orgânica (resultante do baixo ponto de carga zero (PCZ) dessa fração) - pois a fração mineral é composta principalmente de argilas de baixa atividade (MEURER, 2012), a elevação dos teores de MOS é fundamental para a elevação da CTC do solo, e consequente melhoria de sua fertilidade.

Incrementos nos estoques de MOS em área de pastagem e em função da aplicação de cama de peru, são relatados por Pinto et al. (2012), corroborando os resultados desse estudo. Os maiores teores de MOS nas camadas superficiais podem ter ocorrido devido à aplicação superficial, fazendo com que a mineralização da MOS seja mais lenta com menor exposição da mesma aos microrganismos do solo (PINTO et al., 2012). Mesmo em profundidade, ocorreu elevação dos teores de MOS, o que pode ter ocorrido em função de uma possível maior produção de sistema radicular da Urochloa decumbens, reflexo da própria melhoria da fertilidade.

Os teores de $\mathrm{P}$ foram influenciados apenas na camada de 0 a $5 \mathrm{~cm}$. $O$ tratamento controle e a menor dose utilizada, apresentaram os menores teores de P. As doses de 51,79 e $66,24 \mathrm{Mg} \mathrm{ha}^{-1}$ proporcionaram os maiores incrementos nos teores de P. Com 8 anos de adoção do uso de cama de peru a máxima dose de cama de peru aplicada proporcionou incrementos superiores a 9 vezes em relação ao tratamento controle. Comportamento semelhante desse nutriente também foram observados por Pinto et al. (2012), com aplicações de cama de peru em pastagem. Avaliando doses de cama de peru na cultura da cana-de-açúcar, Ribeiro et al. (2016), verificaram incrementos nos teores de $\mathrm{P}$ apenas na camada superficial. Gradientes de concentrações mais elevados do elemento na superfície do solo podem ser observados quando aplicações de diferentes resíduos orgânicos são utilizados superficialmente sem incorporação, sendo essa uma característica do plantio direto (COUTO et al., 2017).

No Bioma Cerrado, com o predomínio de solos altamente intemperizados e com alta capacidade de fixação de $\mathrm{P}$, é muito importante a adequada disponibilidade deste nutriente para a manutenção da produtividade das culturas. Em alguns solos argilosos, a capacidade máxima de adsorção desse elemento pode chegar até 2.636 $\mathrm{mg}$ de $\mathrm{P} \mathrm{kg}{ }^{-1}$ de solo (PINTO et al., 2013). Apesar da alta afinidade das argilas pelo $\mathrm{P}$, sua capacidade de adsorção pode ser reduzida com a correção previa da acidez do solo e a utilização de resíduos orgânico, bem como, esses resíduos promovem maior liberação e aproveitamento do $P$ nativo (SOUZA et al., 2006).

Comportamento distintos, são observados quando as aplicações de diferentes resíduos orgânicos em solos que apresentam baixos teores de óxidos de $\mathrm{Fe}$ e $\mathrm{Al}$, neste caso acumulando mais rapidamente esse elemento (COUTO et al., 2017). Esse fato pode em parte explicar o baixo teor do elemento na área experimental, mesmo após elevadas aplicações de cama de peru. De qualquer modo, se faz evidente que a utilização de resíduos como a cama de peru, que apresentam em sua composição material orgânico, pode ser uma importante ferramenta a fim de promover de forma indireta melhor aproveitamento do P.

Os teores de $\mathrm{K}$ foram influenciados em todas as camadas avaliadas (Tabela 2). Nas camadas de 0 a 5 e 10 a $20 \mathrm{~cm}$, todos os tratamentos com o uso de cama de peru foram superiores ao controle, não apresentando diferenças entre as doses utilizadas. As doses de cama de peru proporcionaram elevação dos teores de $\mathrm{K}$ em aproximadamente 4 e 5 vezes da testemunha para a dose de $35,29 \mathrm{Mg} \mathrm{ha}^{-1}$ e 66,24 $\mathrm{Mg} \mathrm{ha}{ }^{-1}$ respectivamente, na camada de 0 a $5 \mathrm{~cm}$. A camada de 5 a $10 \mathrm{~cm}$ a maior dose proporcionou os maiores teores de $\mathrm{K}$, sendo inferiores no tratamento controle. Entre as doses de cama de peru o menor teor de $\mathrm{K}$ foi na dose com aplicação de $51,79 \mathrm{Mg} \mathrm{ha}^{-1}$.

Apesar da aplicação do resíduo ter sido realizada em superfície nas camadas mais profundas também foram observadas elevação nos teores de potássio em relação ao tratamento controle. Nas camadas de 5 a 10 e 10 a $20 \mathrm{~cm}$, o aumento dos teores de potássio da testemunha em relação a maior dose utilizada foram de mais de 9 e 12 vezes, respectivamente. A elevação nas camadas mais profundas está relacionada com a mobilidade desse em solos tropicais, podendo ser lixiviado para as camadas mais profundas, justificando, portanto, esse resultado. Semelhantemente Pinto et al. (2012), avaliando 
doses de cama de peru em pastagem também constataram resultados parecidos.

Em sistemas de integração lavourapecuária, mesmo em pastejos mais intensivos pode ocorrer teores elevados de $\mathrm{K}$ devido à maior ciclagem do potássio presente nas excreções através de fezes e urina dos animais (FERREIRA et al., 2009). Portanto, as concentrações elevadas desse nutriente em todos os tratamentos em que foram aplicados o resíduo orgânico, a ciclagem desse nutriente promovida pela gramínea e a presença de animais na área pode ter favorecido a manutenção dos elevados teores do mesmo no solo. A quantidade desse elemento ciclado na forma de excreções mesmo em pastejos mais intensos podem como relatado por Ferreira et al. (2009) pode ter favorecido as altas concentrações desse elemento em todos os tratamentos em que foram aplicados cama de peru.

Os teores de $\mathrm{Ca}$ e $\mathrm{Mg}$ foram influenciados pelo uso de cama de peru em todas as profundidades (Tabela 2). Os teores de $\mathrm{Ca}$ elevaram-se na medida em que ocorreu aumento das doses de cama de peru na camada de 0 a 5 $\mathrm{cm}$. A maior dose proporcionou incrementos superiores a 5 vezes em relação ao tratamento controle. Enquanto, os teores de $\mathrm{Mg}$ nessa mesma camada foram menores no tratamento controle e superiores nas doses de 66,24 e 51,79 $\mathrm{Mg} \mathrm{ha}{ }^{-1}$. Nas demais camadas analisadas (5 a $10 \mathrm{e}$ 10 a $20 \mathrm{~cm}), \mathrm{Ca}$ e $\mathrm{Mg}$ apresentaram comportamentos semelhantes. $\mathrm{O}$ tratamento controle apresentou os menores teores de $\mathrm{Ca}$ e $\mathrm{Mg}$, e a utilização de cama, independentemente da dose, se mostrou eficiente em aumentar os teores desses nutrientes, e consequentemente a saturação por bases.

A saturação por bases (V\%) foi influenciada em todas as camadas avaliadas (Tabela 2). Na camada de 0 a $5 \mathrm{~cm}$ do solo, a maior dose de cama de peru foi capaz de elevar em mais de 3 vezes a saturação por bases em relação ao tratamento controle, onde a maior dose chegou a atingir $65 \mathrm{de}$ V\%. As demais doses de cama de peru $\left(35,29\right.$ e $\left.66,24 \mathrm{Mg} \mathrm{ha}^{-1}\right)$ foram intermediárias entre o tratamento controle e a maior dose. Nas demais camadas 5 a 10 e 10 a 20 $\mathrm{cm}$, independente da dose utilizada todas as doses proporcionaram incrementos em relação ao tratamento controle. Na camada 5 a $10 \mathrm{~cm}$, a V\% entre a menor e maior dose variou entre de 45 a $54 \%$ enquanto que a testemunha foi de apenas $9 \%$ refletindo um incremento de 5 vezes entre a testemunha para a menor dose utilizada de cama de peru. Na camada de 10 a $20 \mathrm{~cm}$ houve grandes incrementos entre a testemunha e menor dose, entretanto nessa camada, pouca diferença ocorreu entre as doses de cama de peru. Mesmo nessa camada mais profunda foi possível a elevação da saturação por bases de saindo de 9 e tingindo valores próximos a 40 de V\%. Em todas as profundidades dos tratamentos com a utilização de cama de peru, a saturação por bases foi superior a recomendado para Urochloa decumbens, que é de 30 a 35\% (VILELA; SOUSA; MARTHA JÚNIOR, 2007). Nesse sentido, esses efeitos de utilização de resíduos aviários são importantes, pois se tratando de um dejeto que muitas vezes não tem destino, foi capaz de promover a elevação da saturação agindo como corretivo e fertilizante ao mesmo tempo.

A relação $\mathrm{Ca}: \mathrm{Mg}$ no solo foi afetada somente na camada superficial. No tratamento em que foi aplicado a maior dose de cama de peru a relação $\mathrm{Ca}: \mathrm{Mg}$ foi próximo à 3 sendo superior a testemunha que apresentou relação Ca:Mg de 2, os demais tratamentos ficaram intermediários entre a testemunha e a maior dose. A produtividade de plantas forrageiras parece ser pouco influenciável pela elevação da relação $\mathrm{Ca}: \mathrm{Mg}$, não obtendo-se diferenças em relações Ca:Mg de 1:1, 4:1 ou 6:1 (GUIMARÃES JÚNIOR et al., 2013). Portanto, apesar de alguns resíduos animais poderem ocasionar desbalanços no solo com aplicações contínuas (MENEZES et al., 2017), a relação Ca:Mg manteve-se baixa, variando entre 1,9 e 2,9 entre os tratamentos nas três camadas avaliadas. Esses resultados sugerem que mesmo aplicações contínuas em elevadas quantidades de cama de peru não foram capazes de ocasionar desbalanço entre os elementos Ca:Mg do solo. 
Figura 1. Relação Ca:Mg de um Latossolo Vermelho distroférrico manejado sob pastejo rotacionado em função de doses acumuladas de cama de peru. Médias seguidas por mesma letra não diferem entre si pelo teste de Tukey a $5 \%$ de probabilidade.

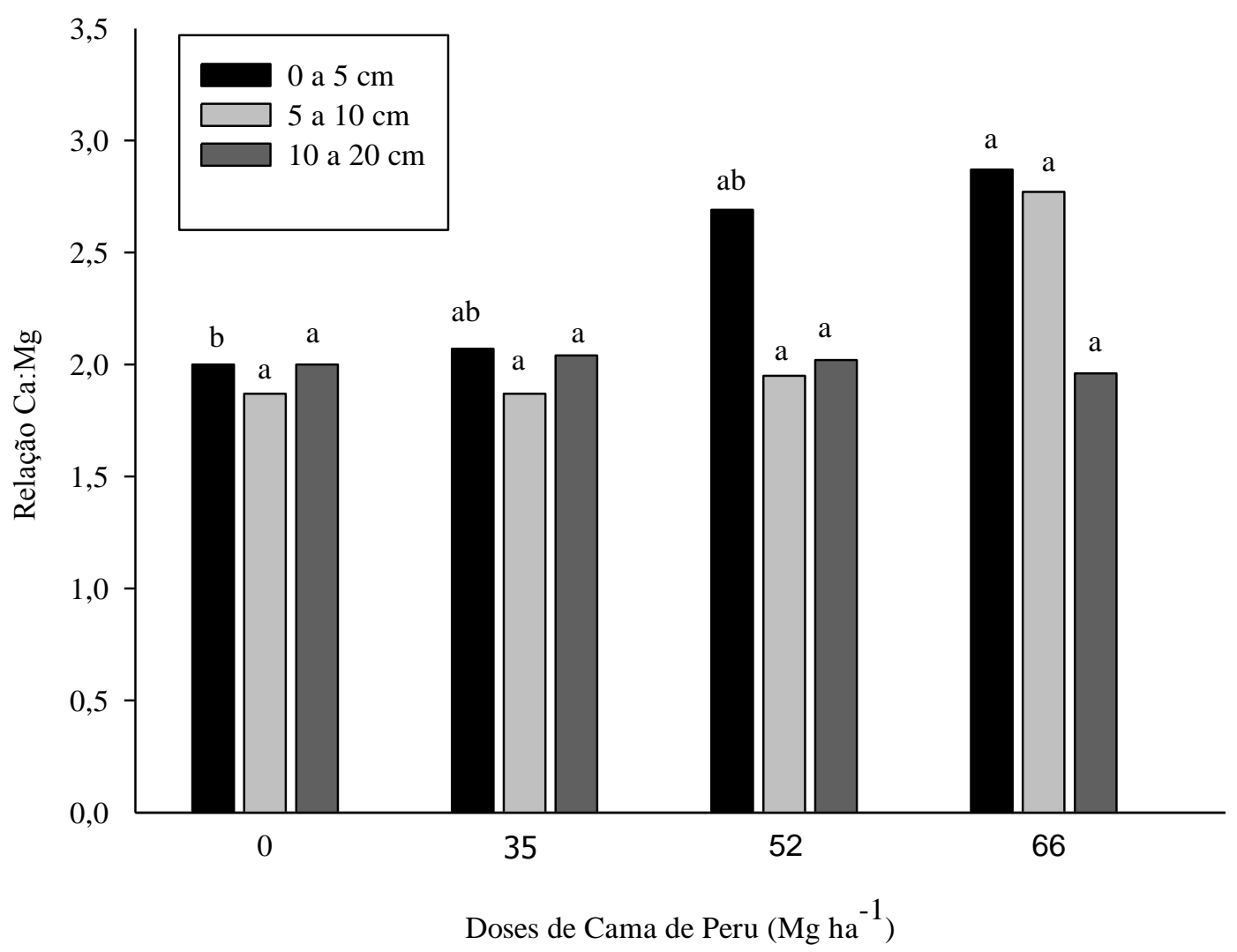

Na camada de 0 a $5 \mathrm{~cm}$, o $\mathrm{Ca}, \mathrm{Mg}$ e $\mathrm{K}$ ocuparam no tratamento controle, respectivamente, 10,$5 ; 5,2$ e $1,2 \%$ da CTC, chegando estas bases trocáveis a atingir na maior dose de cama de peru aproximadamente 44, 16 e $5 \%$ da CTC (Tabela 3). Os teores de Ca nas camadas de 0 a $5 \mathrm{~cm}$ e 10 a $20 \mathrm{~cm}$, foram superiores nos tratamentos em que se utilizou cama de peru, independentemente da dose utilizada, sendo superiores ao tratamento controle. Na camada de 5 a $10 \mathrm{~cm}$, os teores de Ca na CTC foram superiores na dose de 51,79 e $66,24 \mathrm{Mg} \mathrm{ha}{ }^{-1}$, sendo menores no tratamento controle e na menor dose. Os teores de Mg na camada de 0 a $5 \mathrm{~cm}$ foram maiores na maior dose e menor no tratamento controle. Na camada de 5 a $10 \mathrm{~cm}$, as doses de 66,24 e $35,29 \mathrm{Mg} \mathrm{ha}^{-1}$ foram superiores ao tratamento controle. Na camada de 10 a $20 \mathrm{~cm}$, os tratamentos com o uso de cama de peru, independentemente da dose, foram superiores ao tratamento controle. Comportamento semelhante foi observado para o $\mathrm{K}$ na CTC nas camadas de 0 a 5 e 10 a $20 \mathrm{~cm}$. Na camada de 5 a $10 \mathrm{~cm}$, as doses de 66,24 e 35,29 $\mathrm{Mg} \mathrm{ha}^{-1}$ foram superiores à dose de $51,79 \mathrm{Mg} \mathrm{ha}^{-1}$ e o tratamento controle. 
Tabela 3. Saturação de cálcio (Ca), magnésio $(\mathrm{Mg})$ e potássio (K) na CTC de um Latossolo Vermelho distroférrico manejado sob pastejo rotacionado em função de doses acumuladas de cama de peru.

\begin{tabular}{lccc}
\hline Doses & $\mathrm{Ca}^{(1)}$ & $\mathrm{Mg}^{(2)}$ & $\mathrm{K}^{(3)}$ \\
\hline $\mathrm{Mg} \mathrm{ha}^{-1}$ & ---------- \\
\hline \multicolumn{4}{c}{$0 \mathrm{a} 5 \mathrm{~cm}$} \\
0 & $10,5 \mathrm{~b}$ & $5,2 \mathrm{~b}$ & $1,2 \mathrm{~b}$ \\
35,29 & $33,9 \mathrm{a}$ & $13,3 \mathrm{ab}$ & $4,7 \mathrm{a}$ \\
51,79 & $41,9 \mathrm{a}$ & $12,9 \mathrm{ab}$ & $3,8 \mathrm{a}$ \\
66,24 & $44 \mathrm{a}$ & $15,9 \mathrm{a}$ & $5,3 \mathrm{a}$ \\
\hline \multicolumn{5}{c}{$5 \mathrm{a} 10 \mathrm{~cm}$} \\
0 & $5,65 \mathrm{c}$ & $3,1 \mathrm{~b}$ & $0,7 \mathrm{c}$ \\
35,29 & $26,3 \mathrm{~b}$ & $14,6 \mathrm{a}$ & $4,1 \mathrm{ab}$ \\
51,79 & $40,5 \mathrm{a}$ & $11,5 \mathrm{ab}$ & $3,2 \mathrm{~b}$ \\
66,24 & $32,2 \mathrm{ab}$ & $16,7 \mathrm{a}$ & $5,5 \mathrm{a}$ \\
\hline \multicolumn{5}{c}{$10 \mathrm{a} 20 \mathrm{~cm}$} \\
0 & $5,6 \mathrm{~b}$ & $2,8 \mathrm{~b}$ & $0,4 \mathrm{~b}$ \\
35,29 & $23 \mathrm{a}$ & $11,9 \mathrm{a}$ & $3,9 \mathrm{a}$ \\
51,79 & $23,1 \mathrm{a}$ & $12,2 \mathrm{a}$ & $3,7 \mathrm{a}$ \\
66,24 & $22 \mathrm{a}$ & $11,7 \mathrm{a}$ & $4,7 \mathrm{a}$ \\
\hline
\end{tabular}

Médias seguidas por mesma letra não diferem entre si pelo teste de Tukey a $5 \%$ de probabilidade.

Os valores de $\mathrm{Ca}, \mathrm{Mg}$ e $\mathrm{K}$ na CTC para gramíneas em pastejo intensivo variam, respectivamente, entre 55 a $60 \%, 15$ a $20 \%$ e 3 a $6 \%$ (SANTOS et al., 2010). O único elemento que foi considerado ideal foi o $\mathrm{K}$, variando de 3,2 a mais de $5 \%$ na CTC nos tratamentos que foram realizados aplicações de cama de peru nas três camadas de avaliação. O Ca, mesmo a maior dose utilizada não foi suficiente para promover a elevação à teores que são considerados adequados. Esse elemento chegou a atingir no máximo a $44 \%$ com a maior dose utilizada na camada superficial. Nas demais camadas e doses, os teores de Ca variaram entre 22 e $44 \%$ da CTC, ainda, sendo considerados baixos. As porcentagens de $\mathrm{Mg}$ na CTC, variaram entre aproximadamente 12 e $18 \%$ da CTC estando próximo a faixa considerada ideal entre os tratamentos que houve aplicação de cama de peru. Conforme relatado por Menezes et al. (2017), aplicações sequências de resíduos orgânicos podem acarretar ao desbalanço dos nutrientes no solo, portanto, torna-se necessário monitorar aplicações contínua a fim de evitar desbalanço entre os nutrientes. Esse fato desse ser observado principalmente para o elemento potássio nas condições desse estudo, pois a aplicação de maiores doses de cama de peru, poderá exceder os teores considerados adequados, podendo levar a redução da absorção de outros nutrientes como o $\mathrm{Ca}$ e $\mathrm{Mg}$ pela gramínea.

Dentre as variáveis físicas analisadas, somente a macroporosidade foi alterada na camada superficial (Tabela 4). As demais variáveis físicas analisadas não foram afetadas em nenhuma das profundidades. O maior valor de macroporosidade foi observado com a aplicação de $35,29 \mathrm{Mg} \mathrm{ha}^{-1}$ de cama de peru; contudo a menor macroporosidade onde foi aplicado a maior dose do resíduo orgânico $\left(66,24 \mathrm{Mg} \mathrm{ha}^{-1}\right)$. A macroporosidade, bem como a porosidade do solo, pode ser influenciada (principalmente nas camadas superficiais do solo) pelo pastejo, particularmente em condições de maior umidade, o que pode ocasionar ao mesmo tempo o aumento da resistência a penetração (TORRES et al., 2013). Como o período de permanência em cada piquete foi variável em função da oferta de forragem, os tratamentos que receberam maior quantidade de cama de peru, provavelmente produziram mais forragem levando a maior permanência dos animais, o que pode ter levado a redução dos macroporos no tratamento em que foram aplicados $66,24 \mathrm{Mg} \mathrm{ha}^{-1}$ de cama de peru. 
Tabela 4. Atributos físicos de um Latossolo Vermelho distroférrico manejado sob sistema rotacionado de pastejo em função de doses acumuladas de cama de peru.

\begin{tabular}{|c|c|c|c|c|}
\hline $\begin{array}{l}\text { Doses } \\
\text { Mg ha }^{-1}\end{array}$ & $\begin{array}{c}\text { Densidade } \\
\mathrm{Mg} \mathrm{m}^{-3}\end{array}$ & \multicolumn{3}{|c|}{--- } \\
\hline \multicolumn{5}{|c|}{ 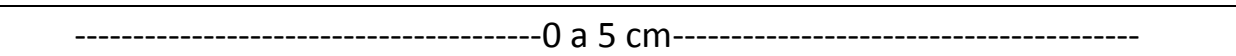 } \\
\hline 0 & $1,12^{\text {ns }}$ & $0,58^{\mathrm{ns}}$ & $0,15 a b$ & $0,43^{\mathrm{ns}}$ \\
\hline 35,29 & 1,07 & 0,64 & 0,19 a & 0,45 \\
\hline 51,79 & 1,04 & 0,64 & $0,17 \mathrm{ab}$ & 0,47 \\
\hline 66,24 & 1,14 & 0,65 & $0,13 \mathrm{~b}$ & 0,52 \\
\hline
\end{tabular}

\begin{tabular}{ccccc}
\hline 0 & $1,12^{\text {ns }}$ & $0,64^{\text {ns }}$ & $0,17^{\text {ns }}$ & $0,47^{\text {ns }}$ \\
35,29 & 1,01 & 0,62 & 0,16 & 0,46 \\
51,79 & 1,07 & 0,57 & 0,14 & 0,43 \\
66,24 & 1,24 & 0,62 & 0,15 & 0,47 \\
& & & & \\
\hline-0 & $1,14^{\text {ns }}$ & $0,62^{\text {ns }}$ & $0,16^{\text {ns }}$ & $0,46^{\text {ns }}$ \\
35,29 & 1,09 & 0,64 & 0,18 & 0,46 \\
51,79 & 1,08 & 0,65 & 0,20 & 0,45 \\
66,24 & 1,06 & 0,60 & 0,16 & 0,46
\end{tabular}

${ }^{\text {NS }}$ Não significativo. *Tratamentos seguidos de mesma letra não diferem estatisticamente pelo teste de Tukey ao nível de $5 \%$ de probabilidade; ${ }^{(1)}$ Volume Total de Poros.

A densidade do solo, microporosidade e volume total de poros (VTP), não sofreram influencia com o aumento da dose de cama de peru em todas as camadas avaliadas (Tabela 4). Avaliando doses de cama de peru na cultura da cana-de-açúcar. Ribeiro et al. (2016), observaram maior VTP e menor densidade do solo quando na maior dose desse resíduo (12 $\mathrm{Mg} \mathrm{ha}^{-1}$ ) aplicado em superfície somente na camada superficial no plantio, diferindo dos resultados encontrados nesse trabalho. Também trabalhando com esse resíduo na cultura da cana-de-açúcar, Gomides e Borges (2014), verificaram efeito na porosidade em camadas superfícies e subsuperficiais quando a aplicação do resíduo ocorreu no sulco de plantio.

A densidade do solo é considerada um importante indicador físico do solo pois interfere nas trocas gasosas, no crescimento do sistema radicular, na resistência a penetração e na dinâmica da água no solo, assim, manejos que não levem à grandes elevações são importantes para qualidade do solo (RESENDE et al., 2012;
PEREIRA et al., 2013). Avaliando níveis de compactação do solo em Latossolo Amarelo, Bonelli et al. (2011) verificaram respostas diferentes em capim mombaça e capim piatã. A produção de matéria seca da arte aérea da parte aérea do capim Mombaça foi reduzido com a elevação da compactação, sendo acentuada a redução de sua produção, quando a densidade do solo foi superior à $1,2 \mathrm{Mg} \mathrm{m}^{-3}$. Porém, a elevação da compactação do solo até $1,6 \mathrm{Mg} \mathrm{m}^{-3}$ não apresentou limitação na produção matéria seca de raízes das duas espécies avaliadas. Com base nos resultados encontrados por Bonelli et al. (2011), a densidade do solo do presente estudo não foi considerada alta em nenhum dos tratamentos avaliados e em nenhuma das camadas estudadas.

Sabe-se que o pisoteio por animais pode causar danos quando associado principalmente a alta umidade do solo, mais comumente a alta umidade na camada superficial (TORRES et al., 2013). O período em que foram amostradas as análises físicas possivelmente por ser uma época 
de início de chuvas não influenciou a densidade do solo devido a menor umidade na época de coleta. O volume total poros não sofreu influência com as doses de cama de peru. De acordo com Kiehl (1979) valores de volume total de poros em solos argilosos variam entre $0,4 \mathrm{e}$ $0,6 \mathrm{~m}^{3} \mathrm{~m}^{-3}$, sendo limitante ao desenvolvimento de plantas quando os valores são menores do que $0,50 \mathrm{~m}^{3} \mathrm{~m}^{-3}$. Desse modo, todos os tratamentos e todas a profundidades analisadas os valores de VTP são considerados elevados.

\section{Conclusões}

A partir de 5 anos de uso continuado de cama de peru (dose acumulada de $51,79 \mathrm{Mg} \mathrm{ha}^{-1}$ ) é possível elevar os teores de fósforo, potássio e a saturação por bases, além de reduzir a acidez e a saturação por alumínio de um Latossolo Vermelho.

A utilização de cama de peru como adubo orgânico por uma maior quantidade de tempo (oito anos consecutivos) é capaz ainda de elevar os teores de matéria orgânica e CTC do solo até a profundidade de $20 \mathrm{~cm}$.

A relação de $\mathrm{Ca}, \mathrm{Mg}$ e $\mathrm{K}$ na $\mathrm{CTC}$ foi aumentada com o incremento de doses de cama de peru. A porcentagem de potássio na CTC manteve-se sempre adequada, variando entre 3,2 a 5,5\% na CTC. As porcentagens de Mg ficaram próximas do adequado. A saturação de $\mathrm{Ca}$ na CTC, no entanto, em todas as profundidades e mesmo na maior dose do resíduo, ficou abaixo dos níveis adequados.

Os atributos físicos (densidade, macro e microporosidade, e volume total de poros), à exceção da macroporosidade na camada de 0 a 5 $\mathrm{cm}$, de um Latossolo Vermelho são pouco influenciados pela utilização de doses crescentes de cama de peru em área com pastejo rotacionado com Urochloa decumbens, mesmo com a adição acumulada de $66,24 \mathrm{Mg}$ ha $^{-1}$ distribuída em oito anos consecutivos de aplicação.

\section{Referências}

ANDREOLA, F.; COSTA, L. M.; OLSZEVSKI, N. Influência da cobertura vegetal de inverno e da adubação orgânica e, ou, mineral sobre as propriedades físicas de uma terra roxa estruturada. Revista Brasileira de Ciência do Solo, Viçosa-MG, v. 24, n.4 p.857-865, jun. 2000. https://doi.org/10.1590/S0100-

$\underline{06832000000400017}$
ABPA. Relatório Anual. São Paulo, 2017.

BONELLI, E. A. et al. Compactação do solo: Efeitos nas características produtivas e morfológicas dos capins piatã e mombaça. Revista Brasileira de Engenharia Agrícola e Ambiental, v.15, p.264269, 2011. https://doi.org/10.1590/S141543662011000300007

COUTO, R. R. et al. Phosphorus fractions in soil with a long history of organic waste and mineral fertilizer addition. Bragantia, v. 76, n. 1, p.155166, mar. 2017. http://dx.doi.org/10.1590/16784499.006.

FERREIRA, E. V. O. et al. Concentração do potássio do solo em sistema de integração lavourapecuária em plantio direto submetido a intensidades de pastejo. Revista Brasileira de Ciência do Solo, Viçosa, n. 33, p.1675-1684, 2009. https://doi.org/10.1590/S0100$\underline{06832009000600016}$

FERREIRA, D.F. SISVAR: um programa para análises e ensino de estatística. Revista Symposium, v. 6, n. 1, p. 36-41, 2011.

GOMIDES, J. N.; BORGES, E. N. Atributos físicos de latossolo cultivado com cana-deaçúcar e adubado com dejetos de animais de criação intensiva. Revista Agrotecnologia, v.5, n.1, p.3349, jul. 2014. https://doi.org/10.12971/21795959/agrotecnologia.v5n1p33-49

GUIMARÃES JÚNIOR, M. P. A. et al. Relação Ca:Mg do corretivo da acidez do solo e as características agronômicas de plantas forrageiras. Revista Brasileira Saúde Produção Animal, Salvador, v. 14, n. 03, p.460-471, 2013. https://doi.org/10.1590/S151999402013000300005

KIEHL, E. J. Manual de edafologia. São Paulo: Agronômica Ceres, 1979.

MENEZES, J. F. S. et al. Long-term application of swine manure on soybean grown in no-till system in Savannah soils. African Journal Of Agricultural Research, v. 12, n. 7, p.487-493, 2017. https://doi.org/10.5897/AJAR2016.11726

MEURER, E. J. Fundamentos de Química do Solo. 5. ed. Porto Alegre: EVANGRAF, 2012. v. 1. 275 p. 
OLIVEIRA, I. P. et al. Efeito da correção da fertilidade do solo no desenvolvimento da Brachiaria brizantha cv. marandu em Latossolo com diferentes históricos. Pesquisa Agropecuária Tropical, v. 01, n. 30, p.57-64, jun. 2000.

PEREIRA, D. C.; WILSEN NETO, A.; NÓBREGA, L. H. P. Adubação orgânica e algumas aplicações agrícolas. Revista Varia Scientia Agrárias, v. 3, n. 2, p.159-174, 2013.

PINTO, F. A. et al. Atributos de solo sob pastejo rotacionado em função da aplicação de cama de peru. Pesquisa Agropecuária Tropical, GoiâniaGO, v.42, n.3, p.254-262, 2012. https://doi.org/10.1590/S1983-

40632012000300002

PINTO, F. A. et al. P-sorption and desorption in savanna brazilian soils as a support for phosphorus fertilizer management. Ciênc. Agrotec., Lavras, v. 37, n. 6, p.521-530, 2013. https://doi.org/10.1590/S141370542013000600005

RESENDE, T. M. et al. Avaliação Física Do Solo Em Áreas Sob Diferentes Usos Com Adição De Dejetos Animais No Bioma Cerrado. Bioscience Journal, v. 28, n. 1, p.179-184, 2012.

RIBEIRO, D. O. et al. Produtividade de cana-deaçúcar e atributos de solo em função da aplicação de cama de peru. Revista de Ciências Agrárias: amazonian journal of agricultural and environmental sciences, v. 59, n. 3, p.259-264, 2016. https://doi.org/10.4322/rca.2215

RIBEIRO, D. O. et al. Organic Fertilization In Soy Farming In A Tropical Region. Australian Journal Of Basic And Applied Sciences, p. 18-22, 2017.

RONDÓN, E. O. O. Tecnologias para mitigar o impacto ambiental da produção de frango de corte. Revista Brasileira de Zootecnia, v. 37, suplemento especial, p. 239-252, 2008. https://doi.org/10.1590/S1516-

\section{8}

SANTOS, P.M.; PRIMAVESI, O.M.; BERNARDI, A.C.C. Adubação de pastagens. In: PIRES, A.V. (Ed.). Bovinocultura de corte. Piracicaba: Fealq, 2010. p.459-472.
SANTOS, H. G.; JACOMINE, P. K. T.; ANJOS, L. H. C.; OLIVEIRA, V. A.; LUMBRERAS, J. F.; COELHO, M. R.; ALMEIDA, J. A.; ARAUJO FILHO, J. C.; OLIVEIRA, J. B.; CUNHA, T. J. F. Sistema de Classificação de solos. Brasília: Embrapa Solos, 2018.

SOUZA, R.F. et al. Calagem e adubação orgânica: influência na adsorção de fósforo em solos. Revista Brasileira de Ciências do Solo, v.30, p.975-983, 2006. https://doi.org/10.1590/S0100$\underline{06832006000600007}$

TEDESCO, M. J.; GIANELLO, C.; BISSANI, C. A.; BOHNEN, H.; VOLKWEISS, S.J. Análise de solo, plantas e outros materiais. 2. ed. Porto Alegre: UFRGS, 1995. (Boletim técnico, 5).

TEIXEIRA, P.C.; DONAGEMMA, G. K.; FONTANA, A.; TEIXEIRA, W. G. Manual de métodos de análise de solo. 3. ed. Brasíia: Embrapa, 2017. 575 p.

TORRES, J. L. R.; RODRIGUES JUNIOR, D. J.; VIEIRA, D. M. S. Alterações nos atributos físicos do solo em função da irrigação e do pastejo rotacionado. Irriga, Botucatu, v. 18, n. 03, p.558-571, 2013. https://doi.org/10.15809/irriga.2013v18n3p558

VILELA, L. et al. Cerrado: uso eficiente de corretivos e fertilizantes em pastagens. Planaltina: Embrapa Cerrados, 2007. Cap. 4. p. 93106. 